\title{
A holistic approach to CSR engagement in palm oil industry
}

Azwan Abdullah ${ }^{1, *}$, Siti Amaliya Mohd Radyi ${ }^{1}$, Mohd Rafi Yaacob ${ }^{1}$, Mohammad Ismail ${ }^{1}$, Mohd Nazri Zakaria ${ }^{1}$, Zulhamri Abdullah ${ }^{2}$

${ }^{1}$ Faculty of Entrepreneurship and Business, Universiti Malaysia Kelantan, Pengkalan Chepa Kelantan, Malaysia

${ }^{2}$ Faculty of Modern Languages and Communication, Universiti Putra Malaysia, Sedang Selangor, Malaysia

\section{A R T I C L E I N F O}

\section{Article history:}

Received 10 March 2017

Received in revised form

4 October 2017

Accepted 5 October 2017

\section{Keywords:}

CSR

Engagement

Community

\begin{abstract}
A B S T R A C T
This study presents a holistic framework in CSR activities by plantation companies that operate internationally. CSR activities are the most powerful element to support the sustainability of plantation operations in the international arena while respecting the available environmental resources. Using qualitative methods, this study has successfully developed a holistic framework that benefits all parties involved in CSR activities, especially in the plantation sector. The findings were based on information provided by respondents through interviews and field work observation method. Indeed, the cooperation of all parties, such as employers, employees, communities and the authorities seek to strengthen CSR activities more effectively and holistically.
\end{abstract}

(C) 2017 The Authors. Published by IASE. This is an open access article under the CC BY-NC-ND license (http://creativecommons.org/licenses/by-nc-nd/4.0/).

\section{Introduction}

Corporate Social Responsibility (CSR) is a short phrase which is very meaningful in people's lives today. CSR represents the concerns, interests and accountability of the supply side and the demand side in the economic cycle. Humanitarian aspects and economic advantages are essentials factors in managing CSR activities. According Secchi (2007) CSR activities are important for a developing country, particularly in maintaining economic development and social welfare in the community.

In this regard, Lee (2008) defined CSR as an ongoing commitment by an organization to conduct business in ethical manners and not just for profitability. At the same time, it also contributes to the economic development and the quality of life improvement to their employees and the local communities.

Little (2006) pointed out that the ongoing initiatives in CSR activities should lead to renewed innovation in a friendlier approach to the interested parties in CSR activities. This is because a good implementation of CSR activities is capable to change the social situation, workplace and community. Holistic approach to CSR can spur the creation of products and services to remain competitive as well

\footnotetext{
* Corresponding Author.

Email Address: azwan.a@umk.edu.my (A. Abdullah)

https://doi.org/10.21833/ijaas.2017.012.004

2313-626X/C) 2017 The Authors. Published by IASE.

This is an open access article under the CC BY-NC-ND license

(http://creativecommons.org/licenses/by-nc-nd/4.0/)
}

as to maintain the continuity of operations of the companies involved. This has led many companies to change the model of the business operations to be in line with CSR activities in order to be more relevant to the society and market environment. This allows a company to operate and maintain performance in a more conducive environment.

Further, Zulhamri and Yuhanis (2013) stated that companies should be responsible for the operations carried out in each of the communities involved. Needs of the community should not be ignored. This is because every form of business operation would affect the society in terms of its social, economic and environmental aspects. According to him, there are companies that allocate great expenditure in CSR activities in order to maintain goodwill and operating performance at the international level, without neglecting the aspects of the environment and society.

This is also acknowledged by Ragodoo (2009) who said that CSR is a means for maintaining contact between entrepreneurs, investors, organizations and society as well as the need for the government's intervention in the legal and regulatory aspects.

However, the implementation of CSR activities still raises many issues. Holistic CSR activities are extremely rare, especially in an operation such as oil palm plantations. This has caused many environmental disasters such as floods, haze, landslides which badly affect the communities involved. Consequently, this study attempts to address the concept of Holistic Framework of CSR 
Engagement Process by Palm Oil Companies in the International Community.

\section{Problem statement}

The understanding of the CSR activities among employers is unbalanced. As CSR activities are conducted in a very formal way by some companies, the effects of CSR engagement by them are very minimal on the communities involved. According to Visser (2005), CSR activities can occur indirectly if a company is concerned with the needs of local communities, taking into account the sensitivities of all parties involved in each operation.

In a different perspective, people have a negative perception toward the employers' involvement in CSR activities. They are seen to have the profit motive only. The local community demands the employers to help ease the burden of their daily lives. Salamon (2010) stated that it is vital for companies to involve in CSR because it is expected to reduce the levels of poverty in local communities maintain the stability of the environmental ecosystems and strengthen the unity within the local community.

Previous research has found that awareness of the community and employers about the importance of involvement in CSR activities is still at the minimum level. In addition, the practice of social accountability is also still at a critical stage. Furthermore, knowledge of the rights of the parties involved and the positive impact in the practice of CSR activities is very low. In this case, Rahim et al. (2011) pointed out that the involvement of companies in CSR activities can improve its reputation in the local and international levels. Nevertheless, the involvement of holistic CSR is extremely difficult to be implemented in reality.

\section{Methodology}

This study aimed to get a real perspective of the parties involved in CSR activities concerning participation, benefits and effects resulted from the activity in the plantation sector.

The study shows findings based on interviews conducted with local residents, workers and community leaders. Several palms own oil plantations owned by Malaysian companies operating abroad have been chosen for this study. Six respondents were interviewed. The results of these interviews were used to publish several research themes that can build a holistic framework model for CSR activities in palm oil plantation sector at the international level.

Among the steps undertaken to complete this study are as follows:

- Identify the locations of the study

- Apply permission from the relevant authorities for the study

- Conduct observations in the study areas
- Hold interviews individually and in groups

- Confirm the findings

- Analyze the results of the study

- Sum up the results of the study

- Publish the findings framework

The results of this study will be transformed into a holistic framework for the implementation of a more effective CSR to all interested parties.

\section{Results and discussion}

The process of obtaining data for this study was conducted by interviewing respondents in stages. Among them are the following:

The first stage : Local leaders

The second stage: Locals

The third stage : The plantation workers

\subsection{The findings of the first stage: Local leaders}

These interviews were done with community leaders involved directly with the plantation companies operating on the area of their administration. A total of two community leaders were interviewed. The results of these interviews have been used to publish some of the themes in the study. Among them are:

\subsubsection{Theme: Responsibility}

The obligations described in this study centered on the leader's responsibility to look after the welfare of the communities in his administrative region to be in the state of harmony at all times. However, when asked about the plantation activities that take place in the area, the community leaders gave different reactions. Leader (1) provided negative perceptions about the plantation companies that carry out activities in the area. Basic infrastructure facilities are very limited, only a school and health clinic. The study also found that the distance between the school and settlements is far. In addition, school building infrastructure is also quite poor. Meanwhile the roads leading to schools are relatively poorly maintained. Similarly, it is the same with health facilities. The health clinic for local residents to seek medical treatment is far from their homes. It is very difficult for people when they have emergencies.

This is also confirmed by the Leader (2) who was interviewed in this research field. He expressed dissatisfaction with the infrastructure provided by the plantation companies operating in his area. This is particularly obvious when looking at the conditions of the road used by them every day. The road is muddy, has potholes and is poorly maintained. The road is uneven as the result of constant movements of large vehicles such as Lorries to and from the plantations. 


\subsubsection{Theme: Concerns}

Concerns in this context are the awareness of local leaders and plantation companies to jointly develop local area. Leaders (1) stated that plantations rarely pay attention to the situations of the local community. Also, plantation operations take place in an environment that is not balanced. The local population hopes that the companies operating in the area to concern a little bit with their basic needs such as food, clothing and schooling. According to the leader (1), this only happens once a year, during festivities. Consequently, the villagers feel that there is no concern for the company to help ease the burden of local residents. The same thing is also expressed by the Leader (2). According to him, there was only one occasion where the plantation company gave a kilogram of green beans for each family as presents to celebrate a festival in the area.

Thus, from the interviews of the leader (1) and Leader (2), the study attempted to validate the reality of these findings by conducting surveys in the field. However, the question that arises is, why do people see it as just the responsibility that must be shouldered on by the plantation operator. Where is the role of the government in this regard? This leads to unbalanced infrastructure development that is supposed to be enjoyed by the locals.

\subsection{The second stage: Locals}

There were two people involved in these interviews. The interviews took place in the residence of the community leaders. The results of these interviews found that the people's awareness and knowledge of their rights are very much limited. Therefore, these two themes are able to support the findings of the study conducted in the first stage before.

\subsubsection{Theme: Awareness}

Local (A) who was interviewed stated that the operators take indifferent attitude to the needs of the local population. The roads built are very limited and poorly maintained. Environmental pollution became rampant, especially during the disposal of plantation waste. Besides that, open burning occurs without regards to the health of the local residents. Local (A) recognized that the authorities' control is very limited in this regard. Open burning occurs widely.

The same thing is also expressed by Local (B). According to him, the awareness of the plantation operator to ensure the population health is not a priority, thus they involve in agricultural activities in a way that is as objective with profit as the main motive. Local (B) acknowledged that while development in their locality grew, it is not on par with the development of oil palm plantations run by these companies.

\subsubsection{Theme: Knowledge}

The interviews conducted found Local (A) and Local (B) acknowledged that plantation activities in their locality happen with rapid progress. However, their knowledge of the rights that should be enjoyed by them is very limited. In this regard, they recognized the plantation activities that took place in the settlement benefit them in the form of economic and financial gains to their lives. At the same time, they felt that the life in the settlements must be harmonized in the context of guaranteed good environment and clean water supply. Nevertheless, the knowledge of their rights is so modestly understood by them and is very limited. Food, clothing and shelter are viewed to cover only the need of everyday life.

In sum, this study found that the second theme gathered from both respondents is the public voice that represents the majority opinion of the locals. The study also seeks to confirm its own findings based on surveys in the field. In this case, it can be concluded that CSR activities cannot be enjoyed by the residents in total. The lack of knowledge and awareness among the population make it more difficult for the involvement in CSR among companies involved.

\subsection{The third stage: The plantation workers}

The last stage in the interview process is to explore the opinion of the workers who are directly engaged in plantation activities in the area. The interviews found that CSR activities cannot take place due to lack of training and exposure given to the employees. Likewise, there was also lack of compliance in the implementation of the duties performed.

\subsubsection{Theme: Training and exposure}

Employee (A) stated that training on the job is provided by the employer to him when he was first to report for work. The training given is more of the technical nature concerning the method of operation and operational aspects of the plantation machinery. Meanwhile, exposure to duties was only obtained through on the job training. According to him, the training was also very little dedicated to environmental care. Everything takes place independently.

Furthermore, the employee (B) has the same opinion. According to him, the company has never had a special training regarding plantation operations; all the knowledge gained is from the observation of the supervisors who oversees the operations of the plantation every day. The training received is limited to meeting the company's objectives and in fact is very little related to workers' relations to environmental preservation and community. 


\subsubsection{Theme: Compliance and actions}

Results from interviews with workers also found the aspects of compliance and actions in the implementation of the task are limited to the instructions by the supervisor at the workplace. The employee (A) admitted that his duties are solely under the directions of supervisors alone.

It is the same for the employee (B). He had no choice to refuse the instructions given. He stated that the source of the instructions given by the supervisors in these fields is based on the assessment given by the employer in administering the oil palm projects.

Based on these interviews, employees (A) and employee (B) underwent routine daily tasks with full compliant and dutiful in every action. They seemed somewhat less attentive on the aspects of environmental care and community which should also be given priority. The study found, this situation occurs because there is no direct involvement of the company in CSR activities in the local area.

Summing up, based on three levels of interviews that have been conducted, a total of six themes were successfully concluded. Among them are the following:

- Awareness

- Concerns

- Knowledge

- Training

- Accountability

- Compliance and Actions

Based on the themes raised in the interviews conducted, it indicates that an action is required to strengthen holistic CSR activities in the plantation sector involved. The need for an ecosystem that is stable and capable of supporting the ongoing CSR activities should be established. Therefore, based on these findings, the study was able to form the framework of plantation companies' involvement in CSR activities more thoroughly.

\section{Recommendations}

Based on the findings that have been analyzed, then a holistic framework in respect to the implementation of CSR by businesses at a global level has been successfully established. The themes findings were detailed in a clear and structured way. The framework is as shown in Fig. 1.

According to Fig. 1, the study has concluded that a holistic ecosystem should be developed to provide better results in the implementation of CSR activities in a community. The elements that make up this ecosystem are an interrelated chain such as awareness, knowledge, training, action and compliance. Understanding of the elements of this chain is important to create a strong foundation in the implementation of CSR. It is the first process that should be prioritized by companies in implementing CSR activities.

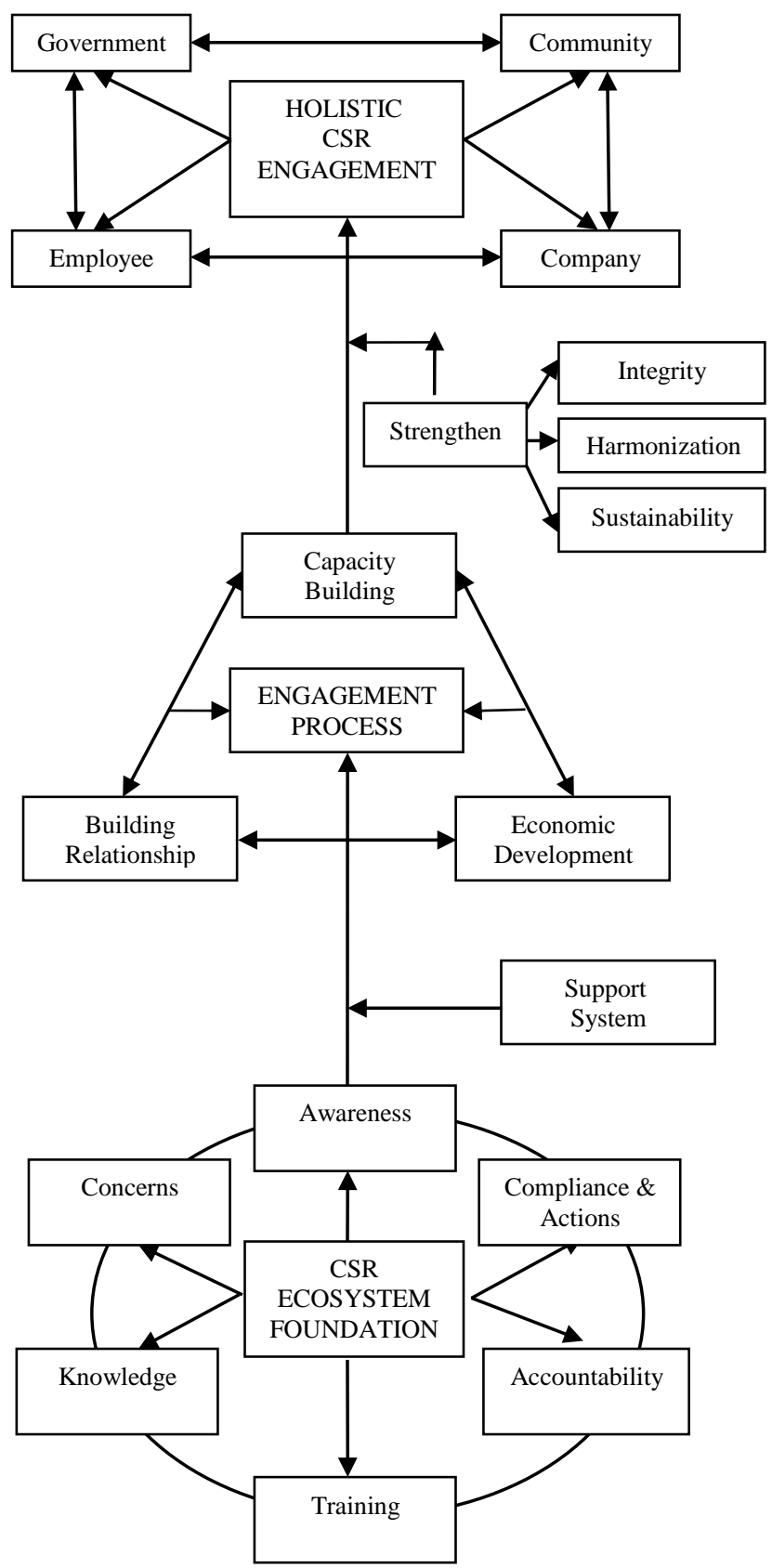

Fig. 1: A Holistic approach to CSR engagement in palm oil industry

The next step, the "engagement process" can then take place simultaneously, which is the "relationship building" aimed to establish long-term relationships with local communities. After that, it is the "capacity building", to develop communities with the skills, knowledge and education. Later step is the involvement in the "economic development", by providing jobs and increasing the income levels and economy of the local community.

The last process is the strengthening of the involvement in CSR activities itself. Effective CSR ecosystem is capable of strengthening the "engagement process". In the end, the involvement in CSR activities is capable of giving holistic impact on the companies, employees, communities and government authorities in the country involved. 
If this holistic framework can be implemented by those who are concerned, it can refute the opinion of Halvorsen (2007) which stated that a company can only carry out CSR as a result of pressure received from stakeholders such as employees and the local community.

Furthermore, when this holistic CSR framework can be successfully implemented, it is in line with the view that the involvement of a company in the long run can become the most powerful instrument to strengthen the bond between shareholders and interested parties. According to Shiu and Yang (2011), the involvement in the ongoing CSR activities can also minimize the risk of property damage and can improve employee morale and the local community while building a reputation in the local and global levels.

Indeed, the involvement in CSR activities can begin as a simple as daily communication process that occurs in the community with the company that runs an operation in the area. Effective communication seeks to create awareness, avoid misunderstandings and at the same time works to improve the knowledge of all parties in more effective implementation of CSR (Eerola, 2013).

\section{Conclusion}

Companies should not involve in CSR activities merely to meet the requirements of the current legislation only. Instead, CSR activity should occur as early as the company begins operations in those communities. Prior to it, a holistic framework must exist in the implementation of CSR so that it can create integrity, harmony and sustainability in an environment that is more conducive to the survival of all parties.

\section{Acknowledgment}

Special Appreciation to Ministry of Higher Education Malaysia (KPT), Universiti Malaysia Kelantan (UMK) and Universiti Putra Malaysia
(UPM) for the approval of Research Grant under Scheme" Research Acculturation Collaboration Effort (RACE)" - reference no: (r/race/a01.00/01134a /001/2015/000236).

\section{References}

Eerola T (2013). A model for stakeholder engagement in mineral exploration in Finland. In the $6^{\text {th }}$ International Conference on Sustainable Development of Minerals Industry (SDIMI'13), Milos Island, Greece: 232-237.

Halvorsen CS (2007). Corporate Social Responsibility: What are the predominant drivers for a company to be socially responsible, and to what extent is CSR integrated with business strategies?. M.Sc. Thesis, University of OSLO, Oslo, Norway.

Lee MDP (2008). A review of the theories of corporate social responsibility: Its evolutionary path and the road ahead. International Journal of Management Reviews, 10(1): 53-73.

Little AD (2006). The innovation highground: Winning tomorrow's customers using sustainability-driven innovation. Strategic Direction, 22(1): 35-37.

Ragodoo NJF (2009). CSR as a tool to fight against poverty: The case of Mauritius. Social Responsibility Journal, 5(1): 19-33.

Rahim RA, Jalaludin FW, and Tajuddin K (2011). The importance of corporate social responsibility on consumer behaviour in malaysia. Asian Academy of Management Journal, 16(1): 119139.

Salamon M (2010). Rethinking corporate social engagement: Lessons from Latin America. Kumarian Press, Sterling, USA.

Secchi D (2007). Utilitarian, managerial and relational theories of corporate social responsibility. International Journal of Management Reviews, 9(4): 347-373.

Shiu Y and Yang S (2011). Does engagement in corporate social responsibility provide insurance-like effect?. Working Paper, Department of Risk Management and Insurance, National Chengchi University, Department of Business Administration, National Cheng Kung University, Tainan, Taiwan.

Visser W (2005). Revisiting Carroll's CSR pyramid: An African perspective. Journal of Business Ethics, 56(2):163-183.

Zulhamri A and Yuhanis AA (2013). Institutionalizing corporate social responsibility: Effect on corporate reputation, culture, and legitimacy in Malaysia. Social Responsibility Journal, 9(3): 344-361. 